\title{
As (des)construções de identidade de gênero na página do facebook "Orgulho de ser Hétero": sob uma abordagem crítica do discurso
}

\author{
Igor Pires Zem El-Dine* \\ Alexandra Bittencourt de Carvalho** \\ Maria Carmen Aires Gomes ${ }^{* * *}$
}

\begin{abstract}
Resumo: Este estudo analisa as construções sociodiscursivas inseridas no contexto da rede social Facebook, investigando as performatizações de identidades de gênero, proferidas na página "Orgulho de ser Hétero". São analisadas imagens, postagens e os seus comentários, com o propósito de compreender como os/as interactantes constroem tais identidades. A análise é fundamentada teoricamente pela perspectiva da Análise do Discurso Crítica proposta por Fairclough ([1992] 2001). Em seguida, pela Análise da Conversação em Rede, proposta por Recuero (2004), bem como pelas "reações sociodiscursivas verbais" propostas por Gomes (2017; 2020, no prelo). Para embasar a discussão sobre performatização de gêneros, recorremos à Butler (2010).
\end{abstract}

Palavras-chave: Análise do Discurso Crítica (ADC). Mídia. Identidade de Gênero. Reação Sociodiscursiva Verbal.

\begin{abstract}
This study analyzes socio-discursive constructions present in the social network website Facebook, investigating gender identity performance, uttered on the page "Orgulho de ser Hétero" (Pride of being Straight). Images, posts, and comments will be analyzed, in order to critically analyze how participants construct such identities. The analysis is theoretically based on the Critical Discourse Analysis perspective proposed by Fairclough ([1992] 2001), on the Network Conversation Analysis proposed by Recuero (2004), and on the "Socio-discursive Reactions" by Gomes (2017; 2020, no prelo). To ground the gender performance discussion, we resort to Butler (2010).
\end{abstract}

Keywords: Critical Discourse Analysis (CDA). Media. Gender Identity. Verbal Socio-discursive Reaction.

Resumen: Este estudio analiza las construcciones sociodiscursivas inseridas en el contexto de la red social Facebook, investigando las performances de identidades de género, elucidadas en la

\footnotetext{
* Mestre pelo Programa de Pós-Graduação em Letras, da Universidade Federal de São João del-Rei (UFSJ). http://orcid.org/oooo-0002-1592-0024 / E-mail: igorpzem@gmail.com

**Doutoranda em Linguística pela Universidade Federal de Minas Gerais (UFMG). http://orcid.org/oooo0003-3159-2021 / E-mail: alexandraportugues@yahoo.com.br

*** Professora Associada III da Universidade Federal de Viçosa (UFV). http://orcid.org/oooo-ooo1-74024353 / E-mail: mcgomes@ufv.br
}

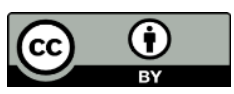

Este artigo está licenciado sob forma de uma licença Creative Commons Atribuição 4.0 Internacional, que permite uso irrestrito, distribuição e reprodução em qualquer meio, desde que a publicação original seja corretamente citada. 
página “Orgulho de ser Hétero". Se analizarán imágenes, publicaciones y sus comentarios con el propósito de comprender cómo los/las interactuantes construyen tales identidades. El análisis es fundamentado teóricamente en la perspectiva del análisis de discurso crítico propuesta por Fairclough ([1992] 2001). Luego, por el Análisis de la Conversación en Red, propuesta por Recuero (2004), así como por las "reacciones sociodiscursivas", propuestas por Gomes (2017; 2020, no prelo). Para basar la discusión sobre performances de género, se recorre a Butler (2010). Palabras clave: Análisis del Discurso Crítico (ADC). Prensa. Identidad de Género. Reacción Sociodiscursiva Verbal.

\section{Considerações iniciais}

O acesso às novas tecnologias, como as Redes Sociais, doravante o Facebook, em especial, ampliou os espaços de discussões sobre os mais variados assuntos e temas. $\mathrm{O}$ Facebook tornou-se, hoje, em meio a esta tecnologização informativa e discursiva, uma ferramenta importante de (inter)ação, comunicação e de (des)construção de conhecimentos.

Os espaços das redes sociais oferecem novas configurações para problematizações que já existiam na esfera pública, como na vida das pessoas de uma forma em geral. Essa nova forma de se comunicar, segundo Recuero (2004, p. 16), “está mudando profundamente as formas de organização, identidade, conversação e mobilização social”.

Fato é que as redes sociais estão modificando (e modificam) as práticas socioculturais e informacionais de nossa vida em sociedade. Os sites de redes sociais são espaços que permitem, portanto, (des)construções de saberes, estabelecimento e negociação de relações de poder, formação de identidades e de relações sociais por parte de seus usuários.

O presente artigo procura analisar a página do Facebook "Orgulho de ser Hétero", através do post e dos comentários que os atores sociais/interacts compartilham em rede, a fim de verificar as possíveis regularidades temáticas, propósitos comunicativos, realizações lexicogramaticais e textuais específicas, as quais podem regulamentar práticas sociais particulares. O nosso objetivo é descrever, interpretar e explanar as construções sociodiscursivas das identidades de gênero e suas relações sociais, 
produzidas no contexto da rede social, investigando as performatizações das masculinidades e das feminilidades iteradas e citadas na referida página.

Aplicaremos os princípios, conceitos e categorias propostos pelos estudos discursivos críticos, para os quais, como propõe Fairclough (2001, p. 95), "o discurso é uma prática, não apenas de representações do mundo, mas de significação do mundo, constituindo e construindo o mundo em significado". O objetivo dessa proposta discursivo-crítica é analisar como os discursos se (re)produzem e/ou legitimam as relações de poder no espaço social midiatizado.

Buscaremos, neste artigo: (i) compreender os modos conversacionais, utilizando as reflexões de Recuero (2004; 2009; 2012; 2014) sobre Conversação em Rede, por meio da categoria analítica proposta por Gomes (2017; 2020, no prelo): reações sociodiscursivas verbais; (ii) repercutir sobre essas implicações sociodiscursivas e políticas (re)produzidas pela mídia digital; para enfim (iii) problematizar acerca das questões relacionadas ao gênero social, sob uma perspectiva discursivo-crítica.

A página "Orgulho de ser Hétero" se define atribuindo valores à suposta supremacia do homem hétero, cujo paradigma está no conceito de heteronormatividade compulsória:

Por heteronormatividade, entende-se a reprodução de práticas e códigos heterossexuais, sustentada pelo casamento monogâmico, amor romântico, fidelidade conjugal, constituição de família (esquema pai-mãe-filho(a)(s). Na paráfrase e cesteira das implicações da aludida palavra, tem-se o heterossexismo compulsório, sendo que, por esse último termo, entende-se o imperativo inquestionado e inquestionável por parte de todos os membros da sociedade com o intuito de reforçar ou dar legitimidade às práticas heterossexuais (FOSTER, 2001, p. 19).

A heteronormatividade implica em tentar padronizar os corpos à luz de um paradigma essencialista, atributivo, hierárquico e patriarcal: modelo baseado no paradigma biologizante (cromossômico) do ser homem e do ser mulher, em que se permite apenas, por exemplo, a união padrão entre homens e mulheres. Todos os corpos, gêneros, que contraponham a tal lógica, são considerados abjetos, anormais, grotescos e muitas vezes não humanos, conforme Butler (2010). 
Este artigo focaliza especificamente a foto de capa da página "Orgulho de ser Hétero" e os espaços de comentários dos interactantes. Na seção 2, discutimos as noções necessárias para o estudo à luz dos conceitos da abordagem discursivo-crítica anglo-saxã e das reflexões sobre identidades e relações de gênero. Na seção 3, apresentamos os procedimentos metodológicos para identificar e avaliar as reações sociodiscursivas verbais. Na seção 4, focalizamos a análise do post e dos comentários dos interactantes, a partir da organização, classificação e codificação dos dados. Na seção 5, estão as considerações finais.

\section{O discurso como categoria explanatória crítica para a perfomatização de gênero}

Para Fairclough (2001), à luz dos estudos discursivos críticos, o discurso pode se referir a qualquer semiose, inclusive à língua, ou qualquer outro elemento de prática social. Para esse analista, o discurso constrói as identidades sociais e as relações sociais entre as pessoas, significando também sistema de conhecimentos e valores. Discurso, nesta perspectiva, é tanto modo de ação quanto de representação, e dialeticamente é moldado e restringido pela estrutura social, qualquer que seja esta estrutura: classe, raça, gênero. Dessa forma, discurso é "uma prática, não apenas de representação do mundo, mas de significação do mundo, constituindo e construindo o mundo em significado.” (FAIRCLOUGH, 2001, p. 91). Assim que, em termos teórico-metodológicos, discurso é, tridimensionalmente, texto, prática discursiva e prática social.

Nesse sentido, Fairclough (2001, p. 96) afirma que "a relação entre discurso e estrutura social seja considerada como dialética para evitar os erros de ênfase indevida; de um lado, na determinação social do discurso e, de outro, na construção do social no discurso". O autor compreende que a realidade social se estrutura dialeticamente:

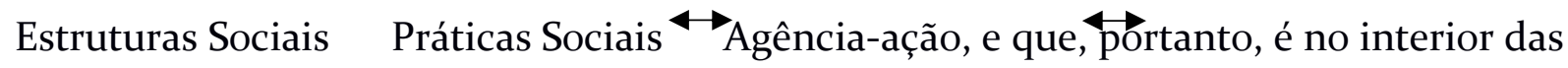
práticas sociais que valores, saberes, poderes, ideologias e lutas hegemônicas são produzidos, mantidos, transformados e iterados (GOMES, 2017). 
As práticas sociais, então, criam condições para o sujeito produzir uma autoconstrução reflexiva, ou seja, os agentes podem formar suas identidades, embora estejam sujeitos a vários tipos de constrangimentos discursivos institucionais, como, por exemplo, os de ordem jurídica, médica ou religiosa. Ramalho e Resende se posicionam da seguinte forma em relação a isso:

\begin{abstract}
os sentidos a serviço da dominação podem estar presentes nas formas simbólicas próprias da atividade social particular ou podem se fazer presentes nas autoconstruções reflexivas, caso a ideologia seja internalizada e naturalizada pelas pessoas. No entanto, a busca pela autoidentidade, que deve ser criada e sustentada rotineiramente nas atividades reflexivas do indivíduo, também pode sinalizar possibilidade de mudança social (RAMALHO; RESENDE, 2006, p. 45).
\end{abstract}

Essas afetações discursivo-ideológicas institucionais, atravessadas por relações de poder, podem implicar na busca pela autoidentidade, caso as ideologias estejam internalizadas e naturalizadas pelas pessoas. No entanto, as atividades reflexivas também são capazes de possibilitar mudanças no âmbito da esfera social. As relações de gênero, por exemplo, se constituem de maneira contraditória em relação aos sujeitos sociais, uma vez que existem muitos dilemas em suas abordagens, originados principalmente pelas contradições institucionais e da sociedade como um todo. Nem todas as pessoas são afetadas da mesma forma e nem todas estão no centro das disputas e das tensões discursivas e ontológicas.

Para Fairclough (2001), os discursos podem entrar em conflito quando diferentes formas de pensar, ver e perceber o mundo são subjetivadas e contestadas por sujeitos particularizados. Assim, o que é contestado são as visões individuais dos sujeitos que constroem o mundo a partir de sistemas pré-construídos, performatizando o mundo à sua imagem. Dessa forma, para Butler, há

várias maneiras como o corpo mostra ou produz sua significação cultural, são performativos [sic], então não há identidades preexistentes na qual [sic] um ato ou atributo possa ser medido; não haveria atos de gêneros verdadeiros ou falsos, reais ou distorcidos, e a postulação de uma identidade de gênero verdadeira se revelaria uma ficção reguladora. (BUTLER, 2010, p. 201). 
A identidade de gênero pode estar associada a um processo de imitação constante e persistente, que passa a ser real. Essa imitação, definida como performativa, sustenta ou desestabiliza os discursos globalizantes que operam o gênero. Para Butler (2010, p. 208), “compreender a identidade como prática é uma prática significante, é compreender sujeitos culturalmente inteligíveis como efeitos resultantes de um discurso amarrado por regras, e que se insere nos atos disseminados e corriqueiros da vida linguística”. Haveria, portanto, uma relação constitutiva entre formação identitária de gênero e discursiva, uma vez que somos interpelados no/pelo discurso. Assim, nós, enquanto sujeitos, somos regulados por atos performativos, e não por uma predeterminação de regras e normas.

Estamos propondo uma articulação entre as discussões ensejadas tanto por Fairclough (2001) quanto por Butler (2010), já que ambos nos permitem compreender que as identidades são atos de criação linguístico-discursivas. Isso quer dizer que as ações éticas não são totalmente determinadas, nem radicalmente livres, o sujeito luta cotidianamente entre os constrangimentos da norma e sua capacidade de ação. É evidente que, para muitos da nossa sociedade, falar de gênero, ou identidade de gênero, ainda é um tabu, é algo que pertence apenas ao espaço privado, embora também nem sempre haja diálogos fomentados sobre tal tema no âmbito familiar.

Tematizar sobre gênero é complexo, porque se constrói o conhecimento com base em alguns "regimes de verdade" e que já estão bastante institucionalizados, como a ciência/biomedicina, religião (GOMES, 2017). É importante compreender que a vida social é aberta, e que há uma complexidade de identidades, de corpos, de formas de viver, de agir e de pensar, regulados por mecanismos e dispositivos de poder, cabendo a nós, sujeitos sócio-histórico-culturais e discursivamente constituídos, olharmos para as questões da sexualidade, sexo e gênero de forma mais igualitária, mais ética (GOMES, 2017), compreendendo que o diferente só existe porque foi produzido por instituições socioculturais que o fizeram assim.

As pessoas não são diferentes porque são pretas, gordas, gays, trans, lésbicas, entre outros eixos identitários, são diferentes porque são discriminadas, violentadas, constrangidas a ter de se enquadrar em um padrão hegemonicamente construído sóciohistórica e culturalmente. Connell (2016, p. 16), prefaciando seu livro Gênero em termos 
reais, chama atenção para a forma pela qual as pessoas enxergam/compreendem o termo gênero; afirma ainda que é uma "questão de experiência cotidiana", pois cada indivíduo o define de maneiras completamente distintas, desde uma leitura anatômico-fisiológica até sua completa fluidez. Connell e Pearse problematizam que

está claro que os corpos são afetados por processos sociais. O modo como nosso corpo cresce e funciona é influenciado pela distribuição de comida, costumes sociais, guerras, trabalho, esporte, urbanização, educação e medicina, para citar apenas as influências mais óbvias. (CONNELL; PEARSE, 2015, p. 93).

Neste mundo plural, o reconhecimento da diferença é crucial, imperativo, já que uma intervenção política efetiva por cidadãos depende de diálogos construídos por meio das diferenças na esfera pública, nos mais variados níveis: locais, regionais e globais. Um ponto importante nessas relações e identidades é abrir um amplo espaço de discussões para possibilitar uma abertura que problematize questões universais e questione o modelo constituído pela sociedade conservadora e tradicional (GOMES, 2017).

É nesse contexto que Butler (2010) problematizará a hierarquia de gêneros e a heterossexualidade e, para tanto, argumentará que identidades são formadas por atos performativos, que produzem corpos no interior das categorias de sexo, tornando-os naturais e originais. Nesse sentido, Gomes (2017) afirma que há uma presunção políticocultural de uma universalidade e unicidade generificada, ou uma construção binária estanque e estática do ser homem e do ser mulher, criando-se um equívoco de se pensar que há uma "ilusão de uma substancialidade prévia, e a interpretação dos efeitos do ritual performático do gênero como emanações necessárias ou consequências casuais desta substância prévia" (BUTLER, 2010, p. 37).

$\mathrm{Na}$ próxima seção, dedicamo-nos a expor os procedimentos teóricometodológicos usados neste estudo, desde a coleta de dados até a análise.

\section{Procedimentos metodológicos}


Este artigo trata-se de um estudo qualitativo e empírico-dedutivo, que busca analisar as construções sociodiscursivas produzidas na rede social Facebook, a partir da página "Orgulho de ser Hétero". A pesquisa qualitativa se configura como um trabalho cujo processo é o próprio texto, pois trata-se de "um conjunto de práticas materiais e interpretativas que dão visibilidade ao mundo" (DENZIN; LINCOLN, 2006 apud RAMALHO; RESENDE, 2011, p. 74).

A Comunicação Mediada por Computador (CMC) é uma proposta metodológica de se pensar os espaços virtuais, que tem propiciado novas maneiras de as pessoas se comunicarem. Para Recuero (2012), a CMC é uma área de estudo já consolidada por meio de estudos relacionados a processos de comunicação humana e realizada através de recursos das tecnologias digitais. Sobre essa questão, Recuero diz que:

dentro desta perspectiva, a comunicação mediada pelo computador compreende práticas conversacionais demarcadas pelas trocas entre atores sociais. Suas características advêm, desse modo, também da apropriação das ferramentas digitais como ambientes conversacionais. (RECUERO, 2012, p. 27).

À luz dos princípios, fundamentos e categorias da Análise de Discurso Textualmente Orientada (ADTO), articulando-se aos estudos de Recuero, Gomes (2017; 2020, no prelo) propõe a categoria: reações sociodiscursivas verbais. Trata-se de um tipo de categoria analítica que atravessa tanto as maneiras de representar quanto as de identificar a si e aos outros, já que, ao assumir uma postura reativa frente aos assuntos e à opinião, à conduta e ao comportamento dos participantes na interação, o/a leitor/a reativo/a estará disputando, além de relações de poder e controle, também relações éticas e morais.

Para Gomes (2020, no prelo), as Reações Sociodiscursivas Verbais dos/as leitores/as são construções sociodiscursivas reativas, cujos ângulos e perspectivas discursivo-ideológicas são direcionados à fala de alguém, ou ao assunto do texto postado, ou a temas marginais e tangenciais. As reações sociodiscursivas verbais podem ocorrer de três formas: (i) Reações transacionais - Interactantes e Reatores/as comentam entre si assuntos e temas, que podem ou não estar vinculados aos textos, estabelecendo a troca sociointerativa; (ii) Reações não-transacionais - Interactante comenta (reage aos) 
assuntos noticiados nos textos jornalísticos, mas sem a troca sociointerativa; e (iii) Reações transacionais atitudinais - Interactantes e Reactantes reagem às trocas, usando citações e falas não só do texto jornalístico, como as de outros/as participantes, de maneira atitudinal.

As reações podem ser tanto direcionadas aos comentários de outros participantes, que são observados, julgados e postos em cenas de interpelação discursiva, quanto podem ser direcionadas aos tópicos (ou mesmo tópicos e temas marginais ao assunto principal), aos fatos ou aos testemunhos usados e representados discursivamente nos textos. Gomes (2017; 2020, no prelo) resgata as premissas, fundamentos e categorias do Sistema de Avaliatividade, propostos, no âmbito da Linguística Sistêmico-Funcional, por Martin e White (2005), White (2004) e ampliado por Eggins e Slade (1997), sobre codificações de atitude para análise de conversações casuais, e propõe seis tipos de reações sociodiscursivas verbais, para a análise de comentários em espaços virtuais:

As reações sociodiscursivas verbais engajadas caracterizam-se pelo nível de comprometimento com o que está sendo dito; em termos linguístico-textuais, realiza-se por meio de modalidades, polaridades (não/sim), concessões, relações lógicosemânticas de extensão ou realce, circunstância de ângulo (Cf. HALLIDAY; MATHIESSEN, 2004).

As reações sociodiscursivas verbais de condenação estão vinculadas às manifestações negativas que implicam certo tipo de ilegalidade, disfuncionalidade, culpa, imoralidade, ou seja, relacionam-se, de maneira negativa, aos julgamentos morais que se associam de alguma forma às instituições legais, refletindo padrões culturais e ideológicos e experiências individuais; isto é, têm a ver com a forma como conceptualizamos o mundo que nos cerca.

As reações sociodiscursivas verbais de admiração se vinculam às manifestações que julgam positivamente as condutas sociais de consideração, respeito e estima, realizadas por meio de atributos, advérbios de comentário e epítetos positivos.

As reações sociodiscursivas verbais de crítica, assim como as reações de admiração, se vinculam aos comportamentos de estima social que julgam negativamente a forma como os indivíduos avaliam os comportamentos, atitudes, capacidade e tenacidade. São manifestações que criticam comportamentos não usuais, incapazes e 
não confiáveis. Realizam-se também por meio de atributos, formas adverbiais, modalidades e epítetos.

As reações sociodiscursivas verbais de aprovação relacionam-se, de maneira positiva, às manifestações elogiosas quanto aos comportamentos éticos, morais e honestos. Associam-se, assim como as reações de condenação, aos valores morais, aos padrões socioculturais e ideológicos produzidos, principalmente, pelas instituições sociais.

As reações sociodiscursivas verbais de apreciação são manifestações afetivas relativas às estéticas, ao valor das coisas, dos objetos, processos e estado de coisas. $\mathrm{Ou}$ seja: referem-se à aparência, construção espacial, tipo de apresentação, mas também do impacto, à reação das pessoas, às questões estéticas de objetos e identidades. Ou seja: avaliam-se, apreciam-se, discursivamente as propriedades.

Quadro 1: Categorias para análise das reações sociodiscursivas verbais

\begin{tabular}{|l|l|}
\hline $\begin{array}{l}\text { Reações Sociodiscursivas verbais } \\
\text { engajadas }\end{array}$ & Refuta, contrapõe, concorda, endossa \\
\hline $\begin{array}{l}\text { Reações Sociodiscursivas verbais } \\
\text { de condenação }\end{array}$ & $\begin{array}{l}\text { Julga moralmente comportamentos de } \\
\text { conduta }\end{array}$ \\
\hline $\begin{array}{l}\text { Reações Sociodiscursivas verbais } \\
\text { de admiração }\end{array}$ & Julga positivamente as condutas sociais \\
\hline $\begin{array}{l}\text { Reaçóes Sociodiscursivas verbais } \\
\text { de crítica }\end{array}$ & Julga negativamente as condutas sociais \\
\hline $\begin{array}{l}\text { Reações Sociodiscursivas verbais } \\
\text { de aprovação }\end{array}$ & $\begin{array}{l}\text { Elogia positivamente comportamentos e } \\
\text { condutas sociais }\end{array}$ \\
\hline $\begin{array}{l}\text { Reações Sociodiscursivas verbais } \\
\text { de apreciaçáo }\end{array}$ & \begin{tabular}{l} 
Avalia qualidades estéticas \\
\hline
\end{tabular}
\end{tabular}

Fonte: Gomes (2017; 2020, no prelo)

As reações sociodiscursivas verbais são um tipo de categoria analítica que permite identificar e analisar as maneiras particulares de representar e de identificar (-se), materializadas em textos, em práticas midiáticas digitais, por meio das interações entre os leitores/as.

\section{Coleta e sistematização do corpus}


O corpus deste estudo constitui-se na foto de capa da página "Orgulho de ser Hétero", cujo recorte temporal compreende o ano de 2016, datado no dia 26 de agosto de 2016 .

A interação mediada virtualmente inicia-se por meio dos comentários dos interactantes ${ }^{1}$. Foram identificadas as reações sociodiscursivas verbais dos participantes, que foram etiquetados como interactantes 1, 2, 3 e assim sucessivamente. Observou-se que, nos comentários, os mesmos estão dialogando com o post da publicação e não entre eles, portanto, são caracterizadas como reações não-transacionais, aquelas em que o interactante comenta (reage aos) assuntos noticiados no post, mas sem a troca sociointerativa.

O post será analisado através das reações dos interactantes, considerando os processos sociodiscursivos produzidos na página do Facebook, o que permitirá fazer a explanatória crítica não só dos discursos ideologicamente cristalizados, mas também das práticas hegemônicas que excluem os considerados diferentes em relação à norma regulatória padrão.

Na próxima seção, iremos analisar e discutir os dados, bem como as reações sociodiscursivas verbais sobre o post e os seus comentários.

\section{Análise e discussão dos dados}

A página do Facebook "Orgulho de ser Hétero" foi criada por Aires, em meados de 2012. Segundo o seu criador, "a página ganhou fama para a alegria dos seus seguidores fiéis e infelicidade dos politicamente corretos". A página "Orgulho de ser Hétero" conta com mais de 1,2 milhões de curtidas e mais de 1,3 milhões de seguidores. Mestre Aires,

\footnotetext{
${ }^{1} \mathrm{O}$ uso do termo interact para se referir-se aos interactantes da interação da página.
} 
como a página o apresenta, é um "hétero normal, nascido em 1991, é apaixonado por mulheres, máquinas automotivas e praticante de musculação, mas jamais dispensa uma cerveja gelada! Se tiver mulher melhor ainda! Mulher de verdade, é claro!”2

Parece-nos que o seu criador entende que a referida página ganhou fama por dois motivos: i) para a alegria dos seus seguidores fiéis e ii) para a infelicidade dos politicamente corretos. Nesse sentido, evidencia uma oposição, porque demarca, na primeira situação, os itens lexicais "seguidores fiéis", exemplificando o público heteronormativo que ofende determinados grupos ou segmentos sociais. Enquanto a segunda situação, a partir dos itens lexicais "politicamente corretos", tipifica o público que evita discursos estereotipados cujas formas de referências podem discriminar o outro, através do racismo, do sexismo, da homofobia, da gordofobia etc. Ademais, o criador da página segue o seu discurso de apresentação, caracterizando sua heterossexualidade como "hétero normal", normatizando, naturalizando e iterando as relações de gênero calcadas na heteronormatividade e no binarismo (BUTLER, 2010).

Há no discurso o uso do item lexical “é”, reforçando o entendimento de que "mulheres" e "máquinas automotivas" estão dispostos num mesmo plano semântico, objetificando e coisificando a mulher. O caráter atributivo de culto ao corpo e de padrões estéticos se faz presente através do ato de dizer "praticante de musculação". A presença do operador "mas" contrapõe conclusões contrárias sobre aquilo que já foi dito anteriormente, porque, apesar de ser "praticante de musculação”, o sujeito social não dispensa uma "cerveja gelada". O autor da página afirma que "Se tiver mulher melhor ainda. Mulher de verdade, é claro!". Os itens lexicais “de verdade” e “é claro” projetam, mais uma vez, um discurso heteronormativo em que a construção descritiva 'mulheres de verdade' se refere ao padrão hegemônico do ser mulher branca, cristã, recatada e do lar. Além do mais, pelo discurso e pela reiteração do "é claro", entende-se que a designação de mulher não compreende as travestis e mulheres trans, nem as mulheres cis ${ }^{3}$ que não performatizam feminilidades, ou seja, que não obedecem a esse padrão normatizado.

\footnotetext{
${ }^{2}$ Disponível em: $<$ http://www.orgulhohetero.blog.br/sobre/>. Acesso em: 18 jun. 2018.

${ }^{3}$ Mulheres Cis: é o indivíduo que se apresenta ao mundo e se identifica com o seu gênero biológico. Por exemplo, se foi considerada do sexo feminino ao nascer, usa nome feminino e se identifica como uma
} 
Interdiscursivamente, relações assimétricas de poder no que tange ao gênero são operadas na página: o sistema ideológico do patriarcado (LAZAR, 2020) parcialmente constrange as escolhas lexicogramaticais descritas anteriormente. Dessa forma, os dispositivos que atuam nesse sistema, sendo eles a emergência da naturalização da heteronormatividade e do binarismo, este último trazendo as performatividades de feminilidades hegemônicas como aceitas e semanticamente boas, refletem a iteração de hegemonias (FAIRCLUGH, 2001) e desigualdades que podem gerar violências de gênero e de orientação sexual. Além disso, a partir de uma presunção valorativa (FAIRCLOUGH, 2003), podemos perceber que, interseccionados ao patriarcado, outros sistemas de opressão atuam discursivamente, como o racismo: o padrão de beleza branco, magro, heterossexual e cis são implícitos ao item lexical "de verdade”. Assim, o dispositivo de racialidade (CARNEIRO, 2005) opera conjuntamente ao do patriarcado, revelando como as violências são complexas e interligadas, mesmo quando não explícitas no discurso.

\section{A capa da página “Orgulho de ser Hétero".}

Figura 1: Captura de tela da foto de capa da página "Orgulho de ser hétero"

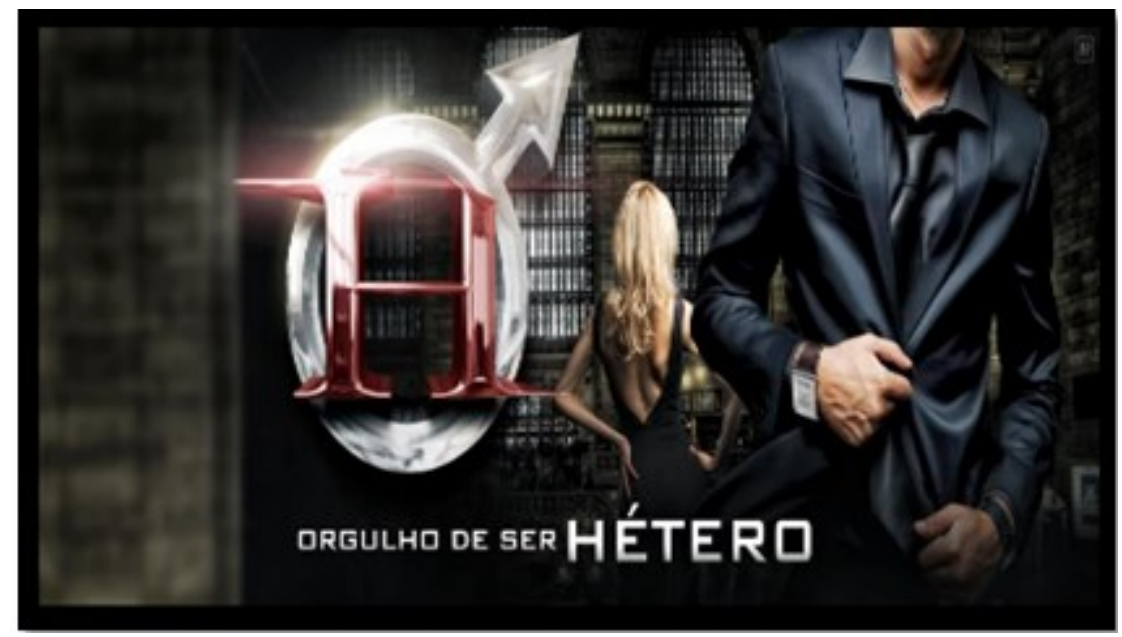

Fonte: Facebook https://www.facebook.com/OrgulhodeserHetero/ Acesso em: 18 jun. 2018.

pessoa deste gênero. Disponível em: <https://universa.uol.com.br/noticias/redacao/2018/03/19/ glossario-de-genero-entenda-o-que-significam-os-termos-cis-trans-binario.htm>. Acesso em: 11 jun. 2018. 
A imagem de capa da página "Orgulho de ser Hétero" foi publicada no dia 26 de agosto de 2016. Em sua composição, há elementos representativos que indicam a figura masculina, revelada pelo poder do homem heterossexual e de símbolos que caracterizam certas performances masculinas aceitas como padrão. No post de capa, evidencia-se um jogo imagético entre três construções semióticas alinhadas: (i) o símbolo de Marte, dentro dele a letra $\mathrm{H}$ em caixa alta e em vermelho, para se referir à masculinidade, representando força, agressão e competição; (ii) alinhando-se ao símbolo de Marte, mais ao fundo, a imagem da mulher, e (iii) a imagem de um sujeito branco, aparentemente bem-sucedido, utilizando terno e relógio sofisticados, de marca, conferindo-lhe certo status social.

O homem parece estar em movimento, pois há um vetor saindo da mão esquerda em direção aos botões do paletó, além de uma gravata semiaberta, sugerindo que o sujeito provavelmente está se despindo. Esse homem metonimicamente representado apresenta atributos que o caracterizam como branco e bem-sucedido. Algumas características físicas podem ser descritas e demarcadas na imagem, como o pomo de adão proeminente, que indica virilidade, bem como as mãos cerradas, que sugerem força física, pelas veias saltadas. Há um cenário moderno, metalizado, ao fundo, contrapondose com a construção cool e viril do símbolo de Marte.

Pode-se perceber, nessa descrição, que, assim como a análise das escolhas lexicogramaticais da seção anterior, a imagem do homem também serve a propósitos hegemônicos do sistema ideológico do patriarcado que versa o "funcionamento complexo do poder e ideologia no discurso, que sustentam (hierarquicamente) arranjos sociais generificados" (LAZAR, 2020, p. 19). Em outras palavras, a imagem de um homem branco, bem-sucedido, implicando uma força física, representa a masculinidade hegemônica, aquela em que os homens agem sobre as mulheres. Discursivamente, a imagem contribui para a manutenção de uma forma de sexismo, que, observada a sua característica relacional, sugere a submissão feminina.

No cenário proposto, há um corpo feminino, em pose de modelo, de costas e de cabelos loiros, branco, magro, utilizando um vestido preto com uma grande fenda nas costas. É um corpo portador de atributos que cria uma cena iterada de uma mulher 
sensualizada e sexualizada, produzindo um corpo objetificado. Para Butler (2010), essa aparência se materializa em um truque performativo da linguagem e/ou em um discurso da heteronormatividade compulsória, que pressupõe aos homens e às mulheres atributos que consideram masculinos e femininos, reforçando de maneira natural um sistema binário e mascarando o discurso hegemonicamente masculino e falocêntrico. $\mathrm{O}$ feminino aparece silenciado, bem como regulamentado, por um teor subversivo e sexualizado.

Pela cena produzida, é possível pensar em duas leituras: (i) a primeira, de que um ato sexual já teria acontecido entre eles ou iria acontecer; (ii) a segunda, de que ela estaria esperando por alguém. Essas interpretações podem ser geradas pelo conteúdo imagético, que elucida um movimento particular do homem, isto é, ele assume uma posição dominadora, enquanto ela está estática, assumindo sua submissão, de costas. Ao fazer isso, generaliza, universaliza e coloca a mulher como um objeto, sem subjetividades, sem identidade, sem rosto, algo ali para ser contemplado e usado.

Observe-se que os corpos, tanto da mulher quanto do homem, são produzidos e representados, pelo olhar do produtor do post, como corpos sem rostos: a mulher é performatizada pelo corpo sensual-sexual, de costas para o leitor, saindo do seu braço um vetor em direção aos glúteos, e o homem, sem rosto, é performatizado pelos acessórios que o classificam como um saber daquilo que se compreende ser um homem heterossexual. A posição dominadora do ator social, juntamente com a articulação dos símbolos representativos da masculinidade, traz significações de virilidade e de potência, exaltando as virtudes do que seria um saber sobre o homem heterossexual. Ou seja, o saber-conhecimento construído sobre o que é ser hétero não exige um rosto, mas um conjunto de atributos que o categorizam como tal.

Essa capa gerou várias reações sociodiscursivas: 48 interactantes "Compartilharam" a foto de capa da página "Orgulho de ser Hétero" e 35 interactantes fizeram "Comentários”. A foto de capa obteve um total de 501 reações, e os interactantes utilizaram a ferramenta emojis para expressarem suas reações, cuja distribuição resultou da seguinte forma: 297 interactantes reagiram marcando a reação "Curtir"; 131 interactantes reagiram utilizando o símbolo da bandeira do movimento LGBTQIA+; 38 interactantes reagiram empregando o símbolo de um coração, atribuído ao sentido de 
"Amei"; 21 interactantes reagiram com uma expressão de "Grr", de raiva; 9 interactantes reagiram utilizando uma expressão "Haha", de risos; 3 interactantes reagiram com uma expressão de "Triste" e 2 interactantes reagiram utilizando a expressão de "Uau", empregado no sentido de satisfação, surpresa ou espanto.

Gráfico 1: Ocorrências das Reações Sociodiscursivas Verbais na foto de capa da página do Facebook "Orgulho de ser Hétero"

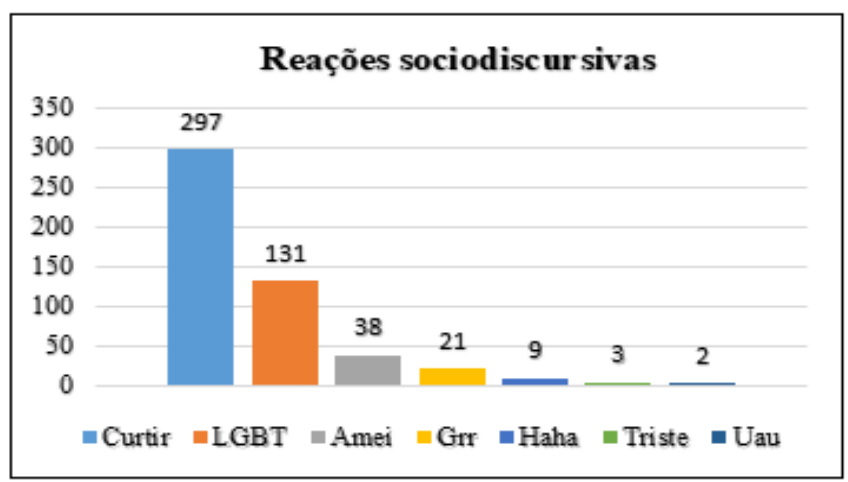

Fonte: Elaborado pelos autores

Figura 2: Os emojis como práticas discursivas de interação

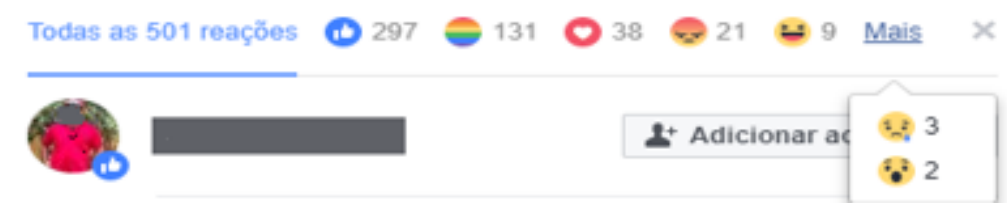

Fonte: Facebook https://www.facebook.com/OrgulhodeserHetero Acesso em: 18 jun. 2018.

As ferramentas 'Curtir', 'Amei' e 'Uau' sinalizam um tipo de reação e interação virtual dos interactantes em, talvez, concordância com as representações socioculturais e políticas construídas na foto de capa da página. A ferramenta 'Curtir' oferece uma ação menos comprometida mediante uma situação comunicativa, porque, de acordo com Recuero (2014, p. 119), "não há elaboração de enunciado para explicar a participação do ator”. Outrossim, as ferramentas 'Grr' e 'Triste’ permitem que os interactantes sinalizem suas contrariedades perante a publicação. Tem-se, também, uma reação interativa, neste 
período, que é a possiblidade de comunicar-se utilizando a bandeira com as cores do arco-íris, símbolo do orgulho LGBTQIA+4.

Paiva (2016), em A linguagem dos Emojis, chama atenção para a função discursiva dos emojis, apontando algumas realizações sintáticas bem significativas: (i) quando os emojis estão inseridos ao final do enunciado, podem funcionar como pontuação, como, por exemplo, a exclamação; (ii) podem ser usados entre pensamentos completos; (iii) mais de um emoji pode construir uma sequência narrativa, ou podem ainda funcionar como marcador de atitude, posicionamento, julgamento ou afeição. No corpus, o 'Haha' pode, por exemplo, ser um tipo de reação irônica, combativa e problematizadora dos agentes sociais acerca da foto de capa da página "Orgulho de ser Hétero", e isso pode ser inferido, porque a capa não tem relação com qualquer tipo de piada, ou humor.

De acordo com Recuero (2014), a ferramenta "Curtir" é entendida como "uma forma de tomar parte na conversação sem precisar elaborar uma resposta. Toma-se parte, torna-se visível a participação, portanto, com investimento mínimo" (RECUERO, 2014, p. 119). Já a ferramenta "Compartilhar" tem a função de ampliar uma informação, isso significa dar maior visibilidade ao circular o conteúdo para um maior número de usuários. A ferramenta "Comentar" sugere "uma ação que não apenas sinaliza a participação, mas traz uma efetiva contribuição para a conversação" (RECUERO, 2014, p. 120).

Na próxima seção, iremos demonstrar as análises das interações e das reações discursivas, a partir das propostas de Gomes (2017; 2020, no prelo), observando o espaço de comentários dos interactantes de forma a aplicarmos os seis tipos de reações: engajadas, de condenação, de admiração, de crítica, de aprovação e de apreciação.

\footnotetext{
${ }^{4} \mathrm{O}$ Facebook liberou essa reação temporária vinculada a eventos importantes. Para o mês de junho, de forma inédita, foi acrescentada a bandeira símbolo da comunidade LGBTQIA+ criada a pedido de Harvery Milk, pelo ativista Gilbert Baker, 1978. Baker faleceu em março de 2017, o que pode ter motivado o Facebook a oferecer a reação. Disponível em: shttp://www.gazetadopovo.com.br/economia/novaeconomia/bandeira-do-arco-iris-e-a-nova-reacao-do-facebook-veja-como-ativa-la 5jlb7ux7nqxowm5xeusze25ty>.Acesso: 22 mai. de 2018.
} 


\section{Análise das interações e das reações sociodiscursivas verbais}

Nesta seção, como já mencionado nos procedimentos metodológicos, evidenciaremos as reações sociodiscursivas verbais, demonstrando a reação ao post e as construções discursivas produzidas e circuladas pelos interactantes. As reações sociodiscursivas são aqueles textos encontrados no espaço destinado aos comentários dos usuários, com base nas temáticas apresentadas pelo post.

A primeira reação discursiva é a de condenação; o interactante 1 constrói o seu entendimento a partir da foto de capa, expressando sua opinião.

Figura 3: Captura de tela de um trecho da postagem do Interact 1

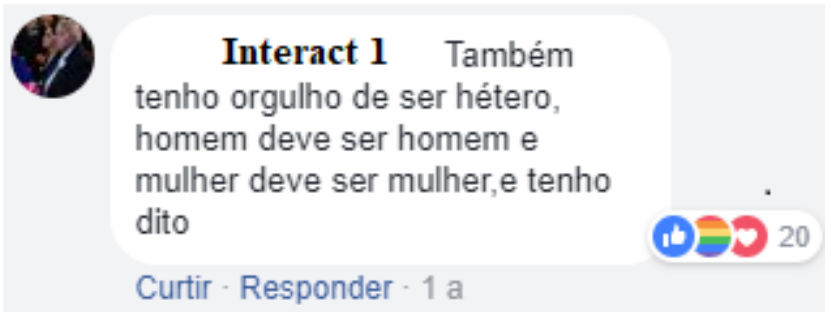

Fonte: Facebook https://www.facebook.com/OrgulhodeserHetero. Acesso em: 18 jun. 2018.

Para o interactante 1, “o homem deve ser homem e a mulher deve ser mulher”. O uso dessa afirmação aponta para uma perspectiva heteronormativa de gênero, que implica em designar performances reguladas socialmente e culturalmente aos homens e às mulheres. Nesta construção discursiva com alto grau de investimento ideológico, por meio de construções deônticas "deve ser" e pela reiteração do "e tenho dito", o interactante 1 define que ter este tipo de orgulho implica em pensar as categorias sociais do "ser homem" e do "ser mulher" como fixas, essencialistas, tal como já demonstrado pelas imbricações da heterossexualidade compulsória.

A estrutura sociocultural e o sistema político de gênero condicionam a prática e adotam um padrão em que ser homem é ser o chefe da família, o protetor do lar, aquele que educa de maneira opressiva e rígida, enquanto a mulher se resumiria a cuidar do lar, 
dos filhos e a fazer compras no supermercado. A mulher é condicionada ao âmbito do privado, da submissão. Por isso, este tipo de construção discursiva itera o conhecimento de que as relações entre gêneros são fixas, atributivas e hierárquicas. A reação sociodiscursiva verbal do interact 1, ao produzir e iterar a relação de gênero desta forma, não reconhece as performatividades representadas pelas comunidades LGBTQIA+, por exemplo, e, por assim dizer, nega ao outro o direito de performatizar seus corpos e gêneros da maneira que se reconhecem.

Já o interactante 2, ao se posicionar, produz duas reações sociodiscursivas: de condenação e de crítica:

Figura 4: Captura de tela de um trecho da postagem do Interact 2

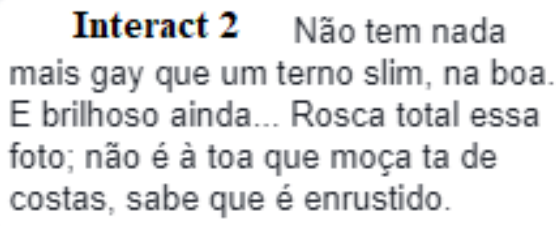

Interact 2 Não tem nada mais gay que um terno slim, na boa. E brilhoso ainda... Rosca total essa foto; não é à toa que moça ta de costas, sabe que é enrustido. Curtir - Responder - 24 sem

Fonte: Facebook https://www.facebook.com/OrgulhodeserHetero Acesso em: 18 jun. 2018.

O interactante 2 identifica que o terno "slim e brilhoso" corresponde a orientação sexual gay, ou seja, não performatiza a identidade do homem heterossexual, conforme a regulação da norma de gênero, tal como a página pretende propor. Nesse comentário, o interactante 2 denomina-se um "puro hétero", vigilantemente atento, ao pontuar (apontar) sua crítica aos administradores da rede. Os atos performativos "não tem nada mais gay", "rosca total”, "sabe que é enrustido" produzem saberes sobre o corpo gay, iterando os insultos normalmente recebidos nas mais variadas situações sociointerativas ao longo da história social. Ao presumir valorativamente por meio de uma reação sociodiscursiva de condenação moral, o ator social masculino identifica as performances do corpo gay, insultando também aqueles ditos héteros seguidores da página.

Os itens lexicais "rosca total", "nada mais gay" e "enrustido" fazem parte da construção de um campo semântico de insultos e hostilidades referidos à comunidade 
gay, iterados por violentos discursos homofóbicos. Fato é que não são apenas léxicos que nomeiam ou definem, mas reforçam uma construção de abjeção, de algo a ser dominado, e injuriado. A iteração desse discurso injurioso e insultuoso gera o reforço do binarismo: quem é normal e quem é diferente.

A utilização do termo "rosca” normalmente refere-se à expressão informal "queima-rosca” que é muito utilizada por pessoas preconceituosas e homofóbicas e tem por objetivo referir-se à prática sexual anal relacionada aos homossexuais. Desse modo, Butler (2010) afirma que o sexo anal entre homens é um exemplo de remembramento radical do corpo, fazendo uma alusão de que a prática seria um tipo de poluição sexual expressiva do desejo de conversar com o corpo (físico e social) intacto. Além do mais, a autora define o termo "abjeto" como aquilo que foi expelido pelo corpo, descartado como excretado, tornando literalmente "Outro" (BUTLER, 2010, p. 230). Em outras palavras, para consolidar "identidades" do "Outro", é provável que identidades culturalmente hegemônicas, no que se refere a diferentes eixos de sexo/raça/sexualidade, se apropriem da exclusão e da dominação, o "Outro", assim, "vira merda” (BUTLER, 2010, p. 231). A questão crucial suscitada é de que a homossexualidade, bem como o sexo anal, torna o homem em um ser gay, ou seja, um corpo abjeto 5 . Esse entendimento pode ser inferido quando o interactante 2 afirma que a mulher está se recusando a ter relações com o masculino pelo fato de identificá-lo como um corpo gay.

A interactante 3 apresenta uma reação sociodiscursiva engajada, levantando o seguinte questionamento:

Figura 5: Captura de tela de um trecho da postagem da Interact 3

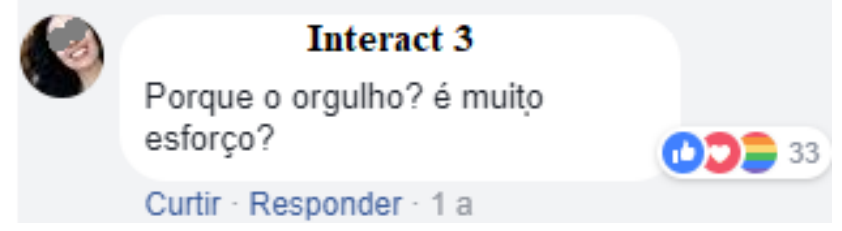

Fonte: Facebook https://www.facebook.com/OrgulhodeserHetero Acesso em: 18 jun. 2018.

\footnotetext{
${ }^{5}$ Para Butler (2010), o corpo abjeto refere-se à existência corporal daqueles que não se encaixam em uma estrutura binária constituída por "homem-mulher".
} 
O comentário do interactante 3 é questionador: "Porque o orgulho? é muito esforço?”. O item lexical “orgulho” produz significados ligados aos sentimentos de prazer, de grande satisfação pessoal com seus próprios feitos e méritos. No entanto, a construção "ter orgulho de algo", dependendo do contexto, pode ser interpretada de maneira pejorativa, trazendo características de soberba, altivez, desdém e arrogância. É o que ocorre no comentário acima: ao usar o intensificador "muito", a interactante 3 questiona/contrapõe o que de fato significa "ter orgulho de ser hétero". Quando uma página se destina a demonstrar o orgulho de ser hétero, presume-se que esteja enaltecendo a heteronormatividade como algo enobrecedor, através de discurso de autoafirmação, de estima, de ato ideológico político e motivado, principalmente, para não reconhecer as diferenças e/ou pluralidades corpóreas.

O uso de interrogações no espaço de comentários dos interactantes é um componente indicativo, questionador e retórico, portanto, argumentativo. A interactante 3 apresenta essa posição engajada, porque confronta este padrão social imposto pela página. Em um movimento intertextual, em que a página dialoga com o orgulho LGBTQIA+, as interrogativas colocam o item lexical "orgulho" em uma luta de sentidos e de disputas. A segunda pergunta “é muito esforço?" revela os privilégios sociais que homens, majoritariamente, brancos cis e de classe média/alta possuem e colocam em xeque o sentido promovido pelos LGBTQIA+ ao escolher lexicogramaticalmente "orgulho". Dessa forma, a contraposição revela a disputa discursiva sobre tal item, demonstrando a inadequação de uma página hétero ao utilizar de tal termo.

\section{Considerações finais}

Buscou-se compreender e refletir acerca das práticas discursivas produzidas na foto de capa da página do Facebook "Orgulho de ser Hétero" e explanar, por meio do post de divulgação e da presença dos comentários dos interactantes, como a página constrói 
práticas hegemônicas excludentes e que normatizam as relações de gênero, além de adotar performatizações sobre o que se entende por ser um homem heterossexual.

O post de divulgação analisado apresenta textos investidos por ideologias preconceituosas por meio de uma padronização das identidades. A construção da Foto de Capa exemplifica essas identidades constituídas por um homem (dominante) e por uma mulher (submissa). A mulher é vista como produto e seu corpo é objetificado, reafirmando a construção de uma identidade que a princípio está em segundo plano. Isso quer dizer que os ataques simbólicos referidos pela página “Orgulho de ser Hétero" às mulheres, às mulheres não femininas ou sensuais, às travestis, às transexuais e aos homossexuais, estão alocados em um estereótipo em que predominam dizeres insultuosos e violentos a partir da construção de enunciados que performatizam as identidades de gênero, como, por exemplo, os itens lexicais utilizados na materialidade linguístico-discursiva: "mulheres de verdade”, "homens devem ser homens", "mulheres devem ser mulheres”, "nada mais gay”, "enrustido” etc.

Assim, a visão de mundo compartilhada pela referida página demonstra um modo de pensar que culturalmente predomina em formas discursivas, por meio do pensamento do patriarcado, assim, a produção do “corpo abjeto” não só promove a diferenciação, mas define os excluídos. Para Butler (2010), o excluído é aquele que em termos sociais não pode existir e essa diferenciação entre pessoas necessita ser desmontada, é tão somente, dessa forma, que as pessoas fora das classificações podem experienciar a liberdade de existir sem serem oprimidas e silenciadas pelo "binarismo" de gênero.

As reações sociodiscursivas verbais que apareceram em nossa análise foram as de condenação e de crítica. Percebemos que os interactantes julgam moralmente as condutas sociais, bem como julgam negativamente as condutas morais. Os agentes sociais reafirmam, por meio de seus comentários, insultos a determinados grupos sociais e iteram ideologias excludentes. As reações sociodiscursivas verbais engajadas são menos recorrentes, isto se deve ao fato de que são poucos os interactantes que tentam problematizar as questões apresentadas pela página. Entretanto, quando eles reagem de forma contrária ao post, geralmente, passam despercebidos e/ou é atribuído a estes interactantes as denominações de "mimizentas", de problematizadores, de defensores dos direitos LGBTQIA+, etc. Isso pode indicar que a negação de certas identidades ou 
de grupos sociais que defendem os direitos de minorias provocam uma espécie de satisfação aos administradores, bem como aos interactantes que seguem e curtem a página.

Logo, pode-se observar que a página "Orgulho de ser Hétero" itera preconceitos, normatizando as relações entre gênero, disseminando ódio contra as comunidades LGBTQIA+ e condicionando a mulher a uma posição secundária. Todas essas relações aplicadas em conformidade com o post analisado se sustentam de fato sobre uma prática hegemônica de homens heterossexuais. Diante do exposto, pode-se perceber a importância da temática na contemporaneidade, uma vez que é preciso refletir sobre as relações identitárias, para, assim, construirmos uma sociedade que respeite as diversidades, além de entender a necessidade de movimentos sociais na luta contra práticas machistas, sexistas e homofóbicas.

\section{Referências}

BUTLER, J. Problemas de gênero: Feminismo e subversão da identidade. Rio de Janeiro: Civilização Brasileira, 2010.

. Relatar a si mesmo: crítica da violência ética. Tradução Rogério Bettoni. 1. ed. Belo Horizonte: Autêntica Editora, 2015a.

A performatividade de gênero e do político. Entrevista concedida a Carla Rodrigues. Revista Cult, São Paulo, n. 205, p. 20-26, 2015 b.

CARNEIRO, A. S. A construção do outro como não-ser como fundamento do ser. Tese (Doutorado em Educação) - Universidade de São Paulo, São Paulo, 2005.

CONNELL, R.; PEARSE, R. Gênero: uma perspectiva global. São Paulo: nVersos, 2015. In: . Gênero em termos reais. São Paulo: nVersos, 2016. p. 16-21.

EGGINS, S.; SLADE, D. Analysing casual conversation. Londres: Cassel, 1997. FAIRCLOUGH, N. Discurso e Mudança Social. Brasília: UNB, 2001. Analysing discourse: textual analysis for social research. London, New York: Routledge, 2003. 
FOSTER, D. W. Consideraciones sobre el estudio de la heteronormatividade en la literatura latinoamericana. Letras: literatura e autoritarismo, Santa Maria, n. 22, jan./jun. 2001.

GOMES, M. C. A. Violência, intolerância e corpo feminino: analisando as reações discursivas na mídia em torno da prática de amamentação. Cadernos de Linguagem e Sociedade (LES), [S. l.], v. 18, p. 175-194, 2017.

. Estudo das reações sociodiscursivas verbais em ambientes de interação virtual.

In: RESENDE, V. M.; ARAÚJO, C. L.; REGIS, J. F. S. (Orgs.). Discurso, política e direitos: por uma análise de discurso comprometida. Brasília: Editora UnB, 2020. No prelo.

HALLIDAY, M. A. K.; MATTHIESSEN, C. An introduction to functional grammar. London: Edward Arnold, 2004.

LAZAR, M. M. Análise de Discurso Crítica Feminista: articulando práxis discursiva feminista e estudos discursivos críticos. In: ; VIEIRA, V. C.; CARVALHO, A. B.

(Orgs.). Práticas sociais, discurso, gênero social: explanações críticas sobre a vida social. Curitiba: Appris, 2020. p. 19-54.

MARTIN, J. R.; WHITE, P. R. R. The Language of Evaluation: Appraisal in English. London: Palgrave Macmillan, 2005.

PAIVA, V. M. O. A Linguagem dos Emojis. Trabalhos em Linguística Aplicada, Campinas, v. 55, n. 2, maio/ago. 2016.

RAMALHO, V.; RESENDE, V. M. Análise de discurso (para a) crítica: o texto como material de pesquisa. Campinas, São Paulo: Pontes Editores, 2011. ; . Análise de discurso crítica. São Paulo: Contexto, 2006.

RECUERO, R. C. Teoria das Redes e Redes Sociais na Internet. Trabalho apresentado no XXVII INTERCOM, na PUC/RS em Porto Alegre. Setembro de 2004.

. Comunidades virtuais em redes sociais na internet: uma proposta de estudos. Porto Alegre: Sulina, 2009. (Coleção Cibercultura).

. A Conversação em Rede: A Comunicação Mediada pelo Computador e as Redes Sociais na Internet. Porto Alegre: Sulina, 2012. (Coleção Cibercultura).

Redes Sociais na internet. Porto Alegre: Sulina, 2014. (Coleção Cibercultura).

WHITE, P. Valoração - a linguagem da avaliação e da perspectiva. Linguagem em (Dis)curso - LemD, Tubarão, v. 4, n. esp, p. 178-205, 2004. 
EL-DINE, Igor Pires Zem; CARVALHO, Alexandra Bittencourt de; GOMES, Maria Carmen Aires

Recebido em 12/o1/2021.

Aprovado em 18/06/2021.

Revista Investigações, Recife, v. 34, n. 2, p. 1 - 25, 2021 ISSN Digital 2175-294x 